\section{D) Check for updates}

Cite this: Dalton Trans., 2019, 48, 107

\title{
Broadband near-IR absorbing Au-dithiolene complexes bearing redox-active oligothiophene ligands $\dagger$
}

\author{
lain A. Wright, (D) * $\ddagger^{\mathrm{a}}$ Claire Wilson, (D) $\S^{\mathrm{b}}$ Simon J. Coles (D) ${ }^{\mathrm{b}}$ and \\ Peter J. Skabara (D)* $\S^{a}$
}

\begin{abstract}
A series of three homoleptic, monoanionic gold dithiolene complexes of oligothiophene ligands which coordinate via a central thiophene-3,4-dithiolate chelate are presented. The oligomer chains are three, five and seven thiophenes long and the complexes display hybrid optoelectronic properties featuring characteristics of both the oligothiophene chains and the delocalised metal dithiolene centre. The properties of the complexes have been characterised using a variety of spectroscopic and electrochemical methods complemented by computational studies. Solid state spectroelectrochemistry has revealed that upon oxidation these complexes display intense and broad absorption across the visible spectrum. In attempting to produce nickel analogues of these materials a single crystal of a photo-oxidised nickel dithiolene complex has also been isolated.
\end{abstract}

Received 28th September 2018
Accepted 15th November 2018

DOI: $10.1039 / c 8 d t 03915 a$

rsc.li/dalton
Conjugated polymers ${ }^{21-24}$ and oligomers ${ }^{25-27}$ of thiophene are archetypical organic p-type semiconductors that have been widely studied for use in optoelectronic devices. Combining the rich optoelectronic properties of the metal-containing noninnocent dithiolene core with the straightforward processing and easily tunable electronic properties of a conjugated polymer or oligomer presents an appealing approach in the search for new functional materials. A number of polymerisable complexes have been realised and subjected to electropolymerisation ${ }^{28-34}$ or electrodeposition ${ }^{35,36}$ to give low band gap metallopolymers, while discrete thiophene-containing dithiolene ligands have recently provided some novel photochromic complexes. ${ }^{37}$
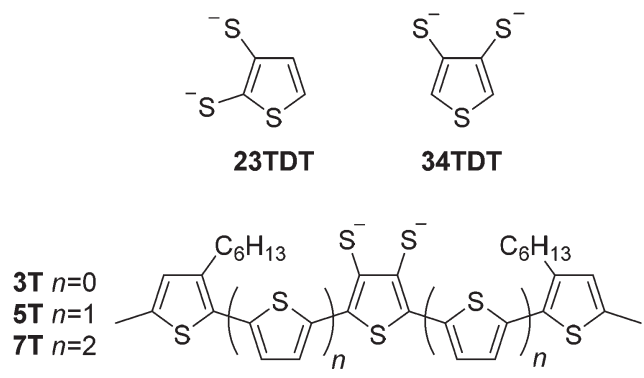

Of particular relevance to this work are the studies by Belo, Almeida and co-workers on complexes of thiophene-dithiolate ligands $s^{38-42}$ which have given rise to a number of complexes and salts thereof with interesting structural, electronic and magnetic properties. ${ }^{43-52}$ The ligands thiophene-2,3-dithiolate 
(23TDT) and thiophene-3,4-dithiolate (34TDT) consist of an aromatic, electron-rich thiophene ring, fused to the electronically delocalised, typically anionic, metal dithiolene chelate. In both 23TDT and 34TDT further functionalisation of the thiophene moiety can be used to modify and tune the materials' electronic or mechanical properties. $\mathrm{Mono}^{-53}$ and di-alkyl ${ }^{54}$ substituted derivatives of 23TDT have been prepared with a dialkyl substituted complex behaving as a single molecule conductor, while robust synthetic routes have been established for the synthesis of semiconducting $\pi$-extended 23TDT ligands bearing aromatic rather than alkyl substituents..$^{55,56}$

Our interest in this area involves extending the conjugation length of the 34TDT ligand. Metallopolymers obtained by the electropolymerisation of complexes of the symmetrical 34TDT ligand 2,5-di(thien-2-yl)thiophene-3,4-dithiolate displayed broad absorption which is desirable for harvesting solar energy. ${ }^{33}$ An analogue of this ligand was synthesised with methyl groups capping the terminal $\alpha$-positions of the oligothiophene chains to inhibit polymerisation; this material provided electrochemically stable complexes. ${ }^{34}$

Our family of ligands has grown to include methyl endcapped terthiophene (3T), quinquethiophene (5T) and septithiophene (7T) chains which we have previously exploited as precursors in the synthesis of new tetrathiafulvalenes ${ }^{57-59}$ and spirocyclic germanium complexes ${ }^{60,61}$ for applications in organic field effect transistor (OFET) and organic solar cell (OSC) devices, respectively. These ligands also bear hexyl groups to improve solubility. Here, we continue these studies by reporting the synthesis of monoanionic homoleptic $\mathrm{Au}$ complexes using 3T, 5T and 7T as 34TDT ligands.

The complexes have been characterised by electrochemical and spectroscopic methods and the optoelectronic properties of the neutral complexes have been probed using electronic absorption spectroelectrochemistry. Alongside this we attempted the synthesis of a complementary Ni complex which proved to be poorly stable, although we did obtain a single crystal of the complex $\left[\mathrm{Ni}(3 \mathrm{~T})_{2}\right]^{2-}$ in a partially oxidised state, the structure of which is also presented.

\section{Results and discussion}

\section{Synthesis}

All of the ligand precursors and complexes were synthesised by the same process (Scheme 1). Full experimental details can be found in our earlier publications ${ }^{57,58,60,62}$ and the ESI. $\dagger$

Hexafluorophosphate salt 1 was treated with $\mathrm{NaHS} \cdot \mathrm{H}_{2} \mathrm{O}$ in a $3: 1$ mixture of $\mathrm{DMF} / \mathrm{AcOH}$ to produce the 1,3-dithiol-2-thione $2 .{ }^{63}$ Compound 2 was dissolved in tetrahydrofuran and treated twice, sequentially, at $-78^{\circ} \mathrm{C}$ with LDA followed by the corresponding 2-thienyl aldehyde 3-5. The temperature had to be carefully controlled throughout this process. This provided intermediate 1,4-diols which were then rapidly oxidised by $\mathrm{MnO}_{2}$ in $\mathrm{CH}_{2} \mathrm{Cl}_{2}$ to give the desired 1,4-diketone intermediates 6-8. Transchalcogenation of the 1,3-dithiol-2-thiones to 1,3dithiol-2-ones 9-11 was achieved with $\mathrm{Hg}(\mathrm{OAc})_{2}$ in a mixture of

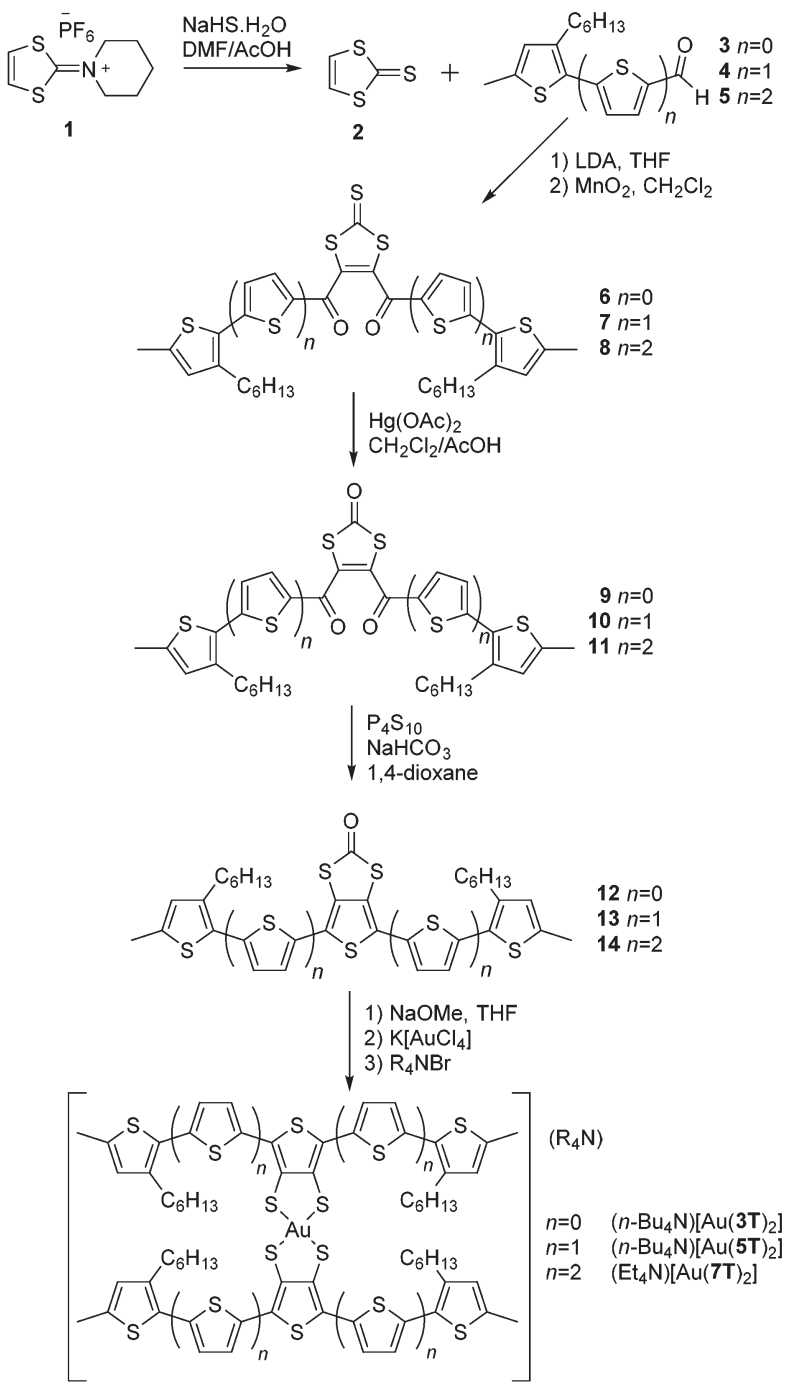

Scheme 1 Synthesis of ligand precursors 12-14 and the Au complexes thereof.

$\mathrm{CH}_{2} \mathrm{Cl}_{2} / \mathrm{AcOH}$. Finally, the 34TDT core was obtained by PaalKnorr cyclisation using $\mathrm{P}_{4} \mathrm{~S}_{10}$ and $\mathrm{NaHCO}_{3}$ in 1,4-dioxane to produce the ring-fused oligothiophenes 12-14.

The final complexes were obtained (Scheme 1) by treating a THF solution of the desired ligand precursor 12-14 with freshly made NaOMe prior to addition of $\mathrm{K}\left[\mathrm{AuCl}_{4}\right]$ followed immediately by a tetra(alkyl)ammonium bromide to provide the complexes in moderate to high yields. Purification was achieved by recrystallisation and verified by elemental analysis. Although the elemental analysis results for the largest complex $\left[\mathrm{Au}(7 \mathrm{~T})_{2}\right]^{-}$ showed some deviation from the predicted values, the results of optical and vibrational spectroscopy and its electrochemical properties are consistent with the other members of the series therefore we will include it within our discussion.

\section{Electronic absorption spectroscopy}

The absorption spectra of the complexes (Fig. 1 and Table 1) were recorded in $\mathrm{CH}_{2} \mathrm{Cl}_{2}$ solution and are dominated by 


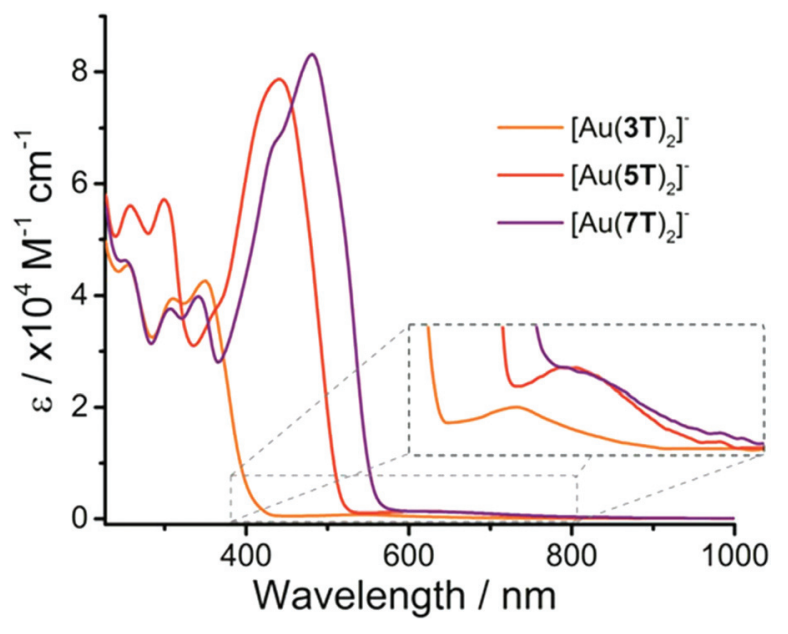

Fig. 1 Electronic absorption spectra for complexes $\left[\mathrm{Au}(3 \mathrm{~T})_{2}\right]^{-},[\mathrm{Au}$ $\left.(5 \mathrm{~T})_{2}\right]^{-}$and $\left[\mathrm{Au}(\mathrm{7T})_{2}\right]^{-}$with low energy $\mathrm{d}-\mathrm{d}$ transitions highlighted (inset).

intense bands in the visible region associated with $\pi \rightarrow \pi^{*}$ transitions over the oligothiophene chains. As may be expected, the $\pi \rightarrow \pi^{*}$ transitions become red-shifted as the conjugation length of the oligothiophene ligand increases. For $\left[\mathrm{Au}(3 \mathbf{3 T})_{2}\right]^{-}$ this band has a $\lambda_{\max }$ at $350 \mathrm{~nm}$ whereas complexes $\left[\mathrm{Au}(\mathbf{5 T})_{2}\right]^{-}$ and $\left[\mathrm{Au}(7 \mathrm{TT})_{2}\right]^{-}$have $\lambda_{\max }$ values of 441 and $481 \mathrm{~nm}$ respectively. These are typical values for oligothiophenes of these chain lengths and are only slightly red-shifted in comparison with the ligands $3 \mathbf{T}-\mathbf{7 T}$.

Common features include two high energy absorptions at $\sim 255 \mathrm{~nm}$ and $\sim 300 \mathrm{~nm}$ which are significantly more intense in complex $\left[\mathrm{Au}(5 \mathrm{~T})_{2}\right]^{-}$. $\left[\mathrm{Au}(7 \mathrm{TT})_{2}\right]^{-}$displays substructure featuring aspects of both of the smaller analogues, including a peak at $\sim 345 \mathrm{~nm}$ which coincides with the lowest energy $\pi \rightarrow \pi^{*}$ band for $\left[\mathrm{Au}(3 \mathbf{3 T})_{2}\right]^{-}$; the peak maximum for $\left[\mathrm{Au}(\mathbf{5 T})_{2}\right]^{-}$correlates closely with a shoulder in the spectrum of $\left[\mathrm{Au}(7 \mathrm{TT})_{2}\right]^{-}$indicating that some spectral characteristics of the smaller chains are maintained as the chain length increases.

The magnitude of the difference in extinction coefficients of the $\pi \rightarrow \pi^{*}$ transitions between the free ligand and the complex decreases systematically as the chain length increases. It more than doubles in the case of $3 \mathrm{~T}$ but increases by only a third in the case of 7T. Calculation of the energy of these $\pi \rightarrow$ $\pi^{*}$ transitions using the onset wavelengths reveals that they have only decreased by $0.04-0.07 \mathrm{eV}$ with respect to their precursor ligands.
A characteristic low energy absorption which stretched towards the NIR region is also observed for each of the complexes and is associated with $\mathrm{d} \rightarrow \mathrm{d}$ transitions over the large $\mathrm{Au}$ atom (Fig. 1, inset). ${ }^{64-66}$ Increasing the ligand size from $\left[\mathrm{Au}(3 \mathrm{~T})_{2}\right]^{-}$to $\left[\mathrm{Au}(5 \mathrm{TT})_{2}\right]^{-}$results in a notable red-shift of this band however it does not shift further when the chain length increases to $\left[\mathrm{Au}(7 \mathrm{~T})_{2}\right]^{-}$. The fact that this band is shifting to longer wavelengths as the oligothiophene chain increases in length serves to indicate that there is indeed some electronic communication with the delocalised dithiolene core.

Combined, these results indicate that while the Au dithiolene core itself does have interaction with the delocalised $\pi$-system of the ligands, it can facilitate only limited electronic communication between the $\pi$-systems of the two ligands, the extent of which decreases with increasing chain length.

\section{Vibrational spectroscopy}

Fourier transform infra-red (FTIR) spectroscopy of the ligands and complexes was performed using $\mathrm{KBr}$ pellets (Fig. 2 and Table S1 $\dagger$ ). There is good complementarity in the fingerprint regions of both the ligands and the complexes.

The ligands 3T-7T display peaks at $\sim 1650$ and $\sim 1700 \mathrm{~cm}^{-1}$ due to the central carbonyl of the thieno-[3,4,d]-1,3-dithiol-2one moiety. This correlates reasonably well with reported values, albeit at slightly higher wavenumber, and can be assigned confidently due to the absence of this peak in the FTIR spectra of the complexes. ${ }^{67,68}$ Aromatic overtones of the thiophene rings dominate the spectrum from $1650-1400 \mathrm{~cm}^{-1}$ (ref. 69) although a peak in this region between $\sim 1560 \mathrm{~cm}^{-1}$ is only observed in the metal complexes (hidden in $\left[\mathrm{Au}(7 \mathrm{TT})_{2}\right]^{-}$) while a weak to medium intensity peak at $\sim 1377 \mathrm{~cm}^{-1}$ arises from deformations of the terminal $-\mathrm{CH}_{3}$ groups. ${ }^{69,70}$ A sharp peak at $\sim 1285 \mathrm{~cm}^{-1}$ is only present in the complexes. By comparing with $\mathrm{Au}$ complexes of 1,2-benzenedithiolate the absence of any intense bands around $\sim 1085 \mathrm{~cm}^{-1}$ indicates that the ligands have no significant radical character. ${ }^{64,66}$ The remaining notable characteristics are bands of moderate to strong intensity between $850-785 \mathrm{~cm}^{-1}$ assigned to aromatic $\mathrm{C}-\mathrm{H}$ stretches of the remaining $\beta$-hydrogens on the thiophene backbone. ${ }^{69,70}$

\section{Cyclic voltammetry}

Cyclic voltammetry was used to examine the electrochemical properties of the complexes (Fig. 3 and Table 2). All of the

Table 1 Peak maxima, extinction coefficients and optical $\pi \rightarrow \pi^{*}$ and $d \rightarrow d$ energy gaps for ligands 3T, 5T and 7T and complexes [Au(3T) $\left.]_{2}\right]^{-}$, [Au $\left.(5 \mathrm{~T})_{2}\right]^{-}$and $\left[\mathrm{Au}(7 \mathrm{~T})_{2}\right]$

\begin{tabular}{lllll}
\hline & $\lambda_{\max } / \mathrm{nm}$ & $\varepsilon_{\max } \times 10^{3} / \mathrm{mol}^{-1} \mathrm{~L} \mathrm{~cm}^{-1}$ & $\pi \rightarrow \pi^{*}$ energy gap $/ \mathrm{eV}$ & $\mathrm{d} \rightarrow \mathrm{d}$ energy gap/eV \\
\hline 3T & $271(\mathrm{sh}), 345$ & 19.7 & 3.03 & - \\
5T & $262,302,435$ & 45.3 & 2.44 & - \\
7T & $260(\mathrm{sh}), 339,467$ & 61.2 & 2.29 & - \\
{$\left[\mathrm{Au}(3 \mathbf{3})_{2}\right]^{-}$} & $254,310,349,543$ & 42.6 & 2.99 & 1.64 \\
{$\left[\mathrm{Au}(\mathbf{5 T})_{2}\right]^{-}$} & $258,299,362(\mathrm{sh}), 441,616$ & 78.6 & 2.24 & 1.42 \\
{$\left[\mathrm{Au}(7 \mathbf{T})_{2}\right]^{-}$} & $251,307,342,438(\mathrm{sh}), 481,611$ & 83.2 & 1.27
\end{tabular}




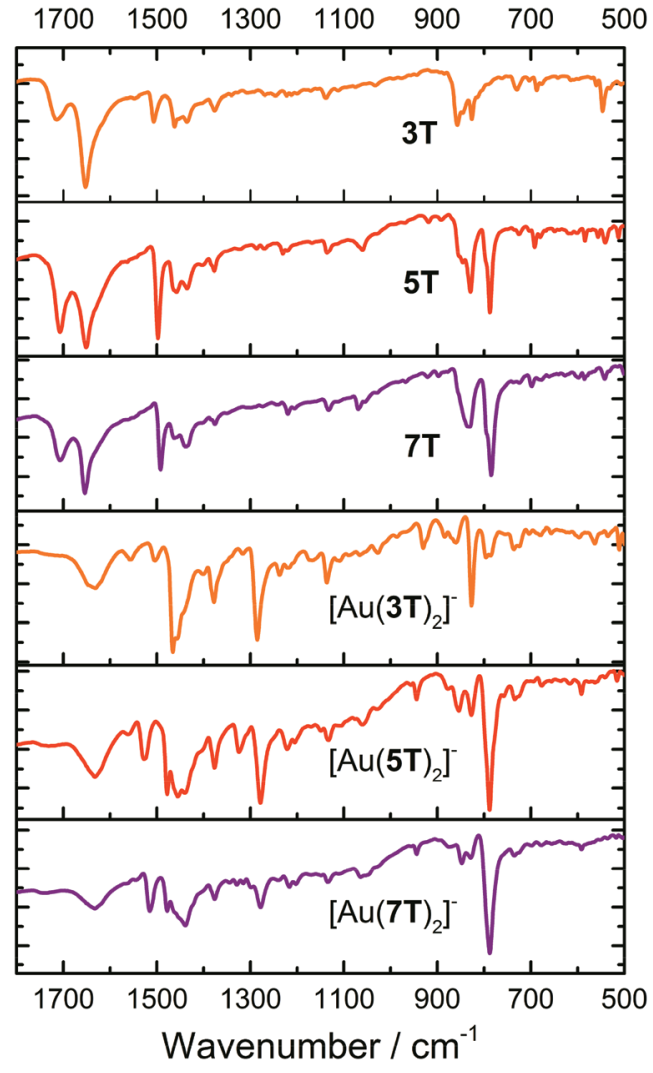

Fig. 2 FTIR spectra for ligand precursors 3T, 5T and 7T and complexes $\left[\mathrm{Au}(3 \mathrm{~T})_{2}\right]^{-},\left[\mathrm{Au}(5 \mathrm{~T})_{2}\right]^{-}$and $\left[\mathrm{Au}(7 \mathrm{~T})_{2}\right]^{-}$.

complexes are significantly more easily oxidised than their ligand precursors ${ }^{57,58}$ and demonstrate a number of reversible or quasi-reversible processes. The complexity of the waveform increases and the reversibility decreases with increasing chain length.

The oxidative behaviour of aromatic Au dithiolene complexes is predominantly ligand based while the reductive behaviour is more metal centered. ${ }^{64,66}$ which can allow for great control to be exerted over the complexes' oxidation potentials. ${ }^{65}$

In this series of compounds all major oxidative processes shift to lower potential as the oligothiophene chain lengthens, due to the increase in the number of $\pi$-electrons and extent of delocalisation, which result in stronger electron donating properties. Using the first oxidation potential as an example, the half-wave potential decreases steadily: $E_{1 / 2}$ of $+0.59 \mathrm{~V}$ for $[\mathrm{Au}$ $\left.(3 \mathrm{~T})_{2}\right]^{-},+0.40 \mathrm{~V}$ for $\left[\mathrm{Au}(5 \mathrm{~T})_{2}\right]^{-}$and $+0.29 \mathrm{~V}$ for $\left[\mathrm{Au}(7 \mathrm{~T})_{2}\right]^{-}$. On the other hand, reduction processes shift to a more positive potential in a similar fashion. The trend in reduction potentials coupled with the low onset of oxidation in all cases further indicates that some electronic coupling between the ligand $\pi$-system and the metal dithiolene core does indeed occur.

Electrochemical HOMO-LUMO gaps were calculated from the difference in the onsets of the first oxidation and reduction
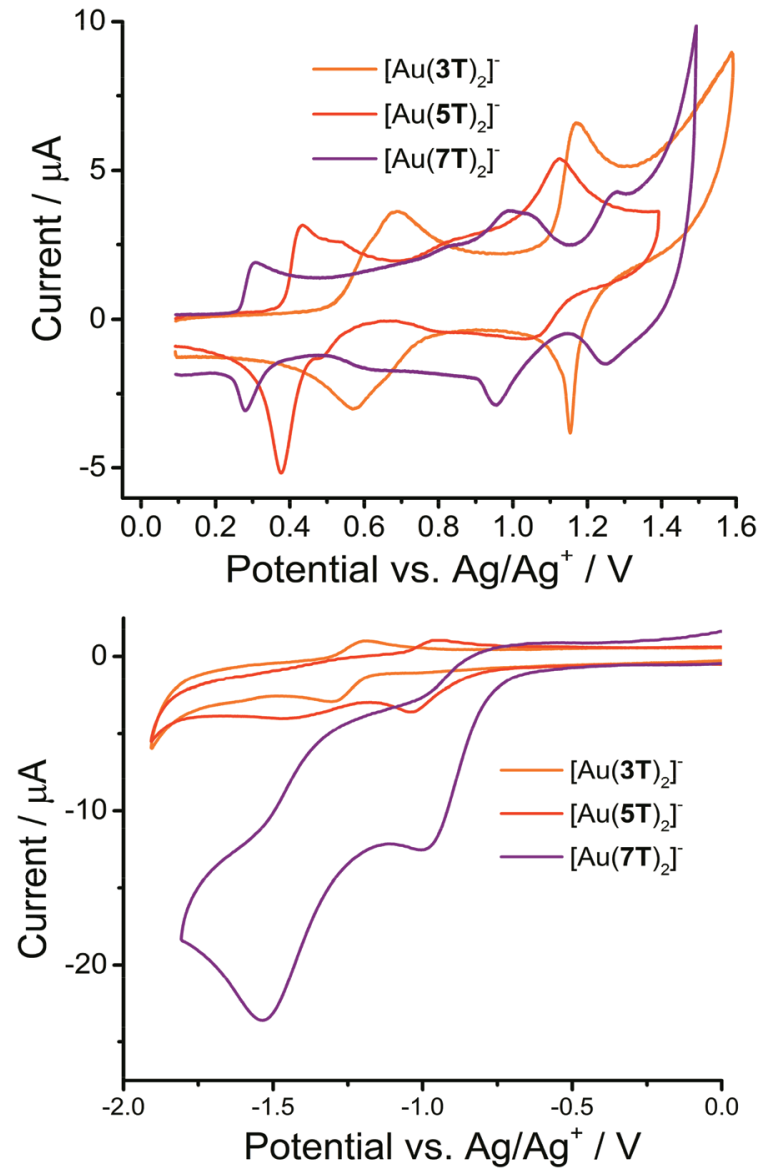

Fig. $3 \mathrm{CV}$ scans for the three gold complexes $\left[\mathrm{Au}(3 \mathrm{~T})_{2}\right]^{-},\left[\mathrm{Au}(5 \mathrm{~T})_{2}\right]^{-}$and $\left[\mathrm{Au}(7 \mathrm{~T})_{2}\right]^{-}$showing oxidation (upper) and reduction (lower) events.

Table 2 Electrochemical data for $\left[\mathrm{Au}(3 \mathrm{~T})_{2}\right]^{-},\left[\mathrm{Au}(5 \mathrm{~T})_{2}\right]^{-}$and $\left[\mathrm{Au}(7 \mathrm{~T})_{2}\right]^{-}$

\begin{tabular}{llll}
\hline & {$\left[\mathrm{Au}(3 \mathrm{3T})_{2}\right]^{-}$} & {$\left[\mathrm{Au}(5 \mathrm{TT})_{2}\right]^{-}$} & {$\left[\mathrm{Au}(7 \mathrm{TT})_{2}\right]^{-}$} \\
\hline$E_{1 \mathrm{ox}} / \mathrm{V}$ & $+0.61 / 0.57$ & $+0.43 / 0.38$ & $+0.31 / 0.28$ \\
$E_{2 \mathrm{ox}} / \mathrm{V}$ & $+0.69 / 0.64$ & $+0.53 / 0.47$ & $+0.83 / 0.63$ \\
$E_{3 \mathrm{ox}} / \mathrm{V}$ & $+1.17 / 1.15$ & $+0.88 / 0.80$ & $+0.99 / 0.95$ \\
$E_{\text {ox }} / \mathrm{V}$ & - & $+1.12 / 1.04$ & $+1.04^{\text {irr }}$ \\
$E_{1_{\text {red }}} / \mathrm{V}$ & $-1.30 / 1.19^{q}$ & $-1.04 / 0.95^{q}$ & $-1.00^{\text {irr }}$ \\
$E_{2 \text { red }} / \mathrm{V}$ & - & - & $-1.53^{\text {irr }}$ \\
HOMO-LUMO gap $/ \mathrm{eV}^{a}$ & 1.68 & 1.19 & 1.04
\end{tabular}

${ }^{a}$ Electrochemical HOMO-LUMO gap calculated as the difference between the onset of the first oxidation and reduction waves. ${ }^{q}$ Quasireversible peak. ${ }^{i r r}$ Irreversible peak.

peaks and agree well with the $\mathrm{d} \rightarrow \mathrm{d}$ transition energies calculated from the absorption spectra.

Some specific comments about each complex follow:

$\left[\mathrm{Au}(3 \mathbf{3 T})_{2}\right]^{-}$

This complex displays greatly improved electrochemical reversibility when compared to the analogous non-capped complex which only had a single irreversible oxidation at +0.57 $\mathrm{V} .{ }^{34}$ It has closely overlapping first and second oxidations with peak profiles and separations that indicate fairly good reversi- 
bility. In keeping with our previous observations we have assigned this to sequential radical cation formation on each terthiophene, which is localised primarily over the ligands. A third quasi-reversible oxidation occurs at $E_{1 / 2}$ of $+1.16 \mathrm{~V}$, of which the narrow profile of the reverse peak may indicate some adsorption of the triply charged complex to the electrode surface. The complex undergoes a single quasi-reversible reduction at $-1.26 \mathrm{~V}$.

$\left[\operatorname{Au}(\mathbf{5 T})_{2}\right]^{-}$

In complex $\left[\mathrm{Au}(\mathbf{5 T})_{2}\right]^{-}$, the first oxidation peaks are similar to those observed for complex $\left[\mathrm{Au}(3 \mathbf{3})_{2}\right]^{-}$. The next region of the voltammogram shows no clearly defined peaks although there is evidence for a further oxidation occurring at approximately $+0.83 \mathrm{~V}$ followed by a fourth, more easily discernible quasi-reversible peak centred at $E_{1 / 2}=+1.08 \mathrm{~V}$. This sequence of events is likely due to dication formation on each of the quinquethiophene chains. The complex undergoes a single quasi-reversible reduction at $E_{1 / 2}=-1.00 \mathrm{~V}$ and an irreversible reduction at $-1.48 \mathrm{~V}$.

$\left[\mathrm{Au}(7 \mathrm{~T})_{2}\right]^{-}$

Complex $\left[\mathrm{Au}(7 \mathrm{TT})_{2}\right]^{-}$displays a voltammogram with a shape that is largely complementary to that of $\left[\mathrm{Au}(\mathbf{5 T})_{2}\right]^{-}$. A first reversible oxidation is centered at $+0.28 \mathrm{~V}$ with another oxidation at $+0.97 \mathrm{~V}$. There appears to be at least one quasi-reversible oxidation in the broad waveform between these two oxidations. An irreversible shoulder can be identified at $+1.04 \mathrm{~V}$ prior to the final quasi-reversible formation of a second dication at $+1.27 \mathrm{~V}$. The complex undergoes two irreversible reductions at -1.00 and $-1.53 \mathrm{~V}$. The magnitude of the current response of these reductions is very large and no reversibility is apparent.

\section{Computational studies}

DFT methods were used to gain a further insight into the electronic properties of $\left[\mathrm{Au}(3 \mathbf{3 T})_{2}\right]^{-}$and $\left[\mathrm{Au}(\mathbf{5 T})_{2}\right]^{-}$. The orbital contours for $\left[\mathrm{Au}(3 \mathrm{TT})_{2}\right]^{-}$and $\left[\mathrm{Au}(5 \mathrm{~T})_{2}\right]^{-}$are shown in Fig. 4 and 5 respectively. As it was desirable to see how the hexyl chains influence the geometry adopted by the ligands upon complexation they were included in the calculation. Similar observations can be made for both complexes:

(1) In both cases steric hindrance results in significant twisting of the terminal thiophene rings of the oligothiophene chains

(2) The frontier orbitals of the HOMO manifold are delocalised over both the oligothiophene chains and metal dithiolene core. $\operatorname{In}\left[\mathrm{Au}(\mathbf{5 T})_{2}\right]^{-}$it is not until the HOMO-4 that purely oligothiophene based contours begin to be observed while in $\left[\mathrm{Au}(3 \mathrm{~T})_{2}\right]^{-}$even the HOMO-5 contains some influence from the coordinating sulfurs.

(3) The LUMO is localised almost exclusively over the golddithiolene centre for both complexes and is close in energy to the higher HOMO orbitals which correlates well with the low energy $\mathrm{d} \rightarrow \mathrm{d}$ band observed in the absorption spectra.

(4) The LUMO+1 and higher lie at significantly more positive energies than the LUMO and are delocalised over the conjugated $\pi$ systems of the ligands with small contributions from
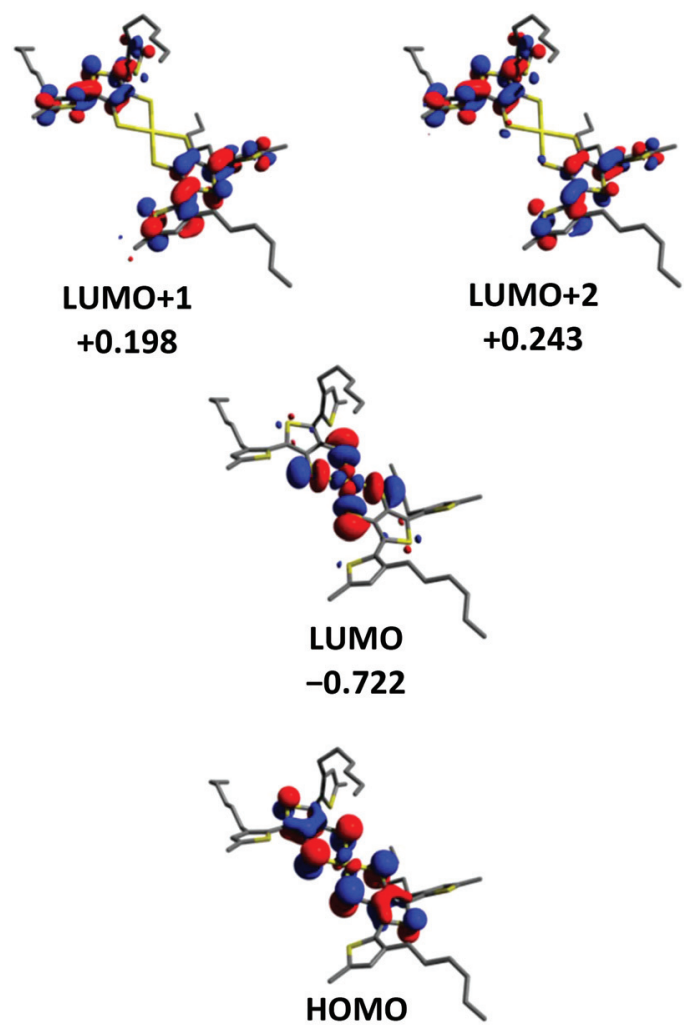

$-1.866$
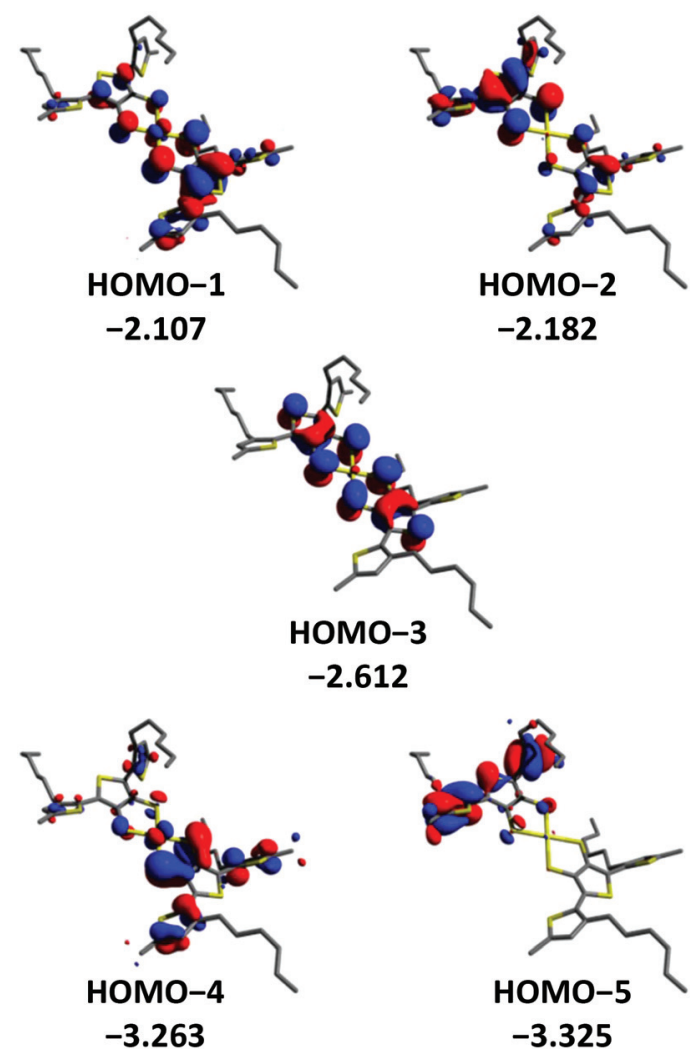

Fig. 4 Frontier orbital profiles and energies for the $\left[\mathrm{Au}(3 \mathrm{~T})_{2}\right]^{-}$anion. 

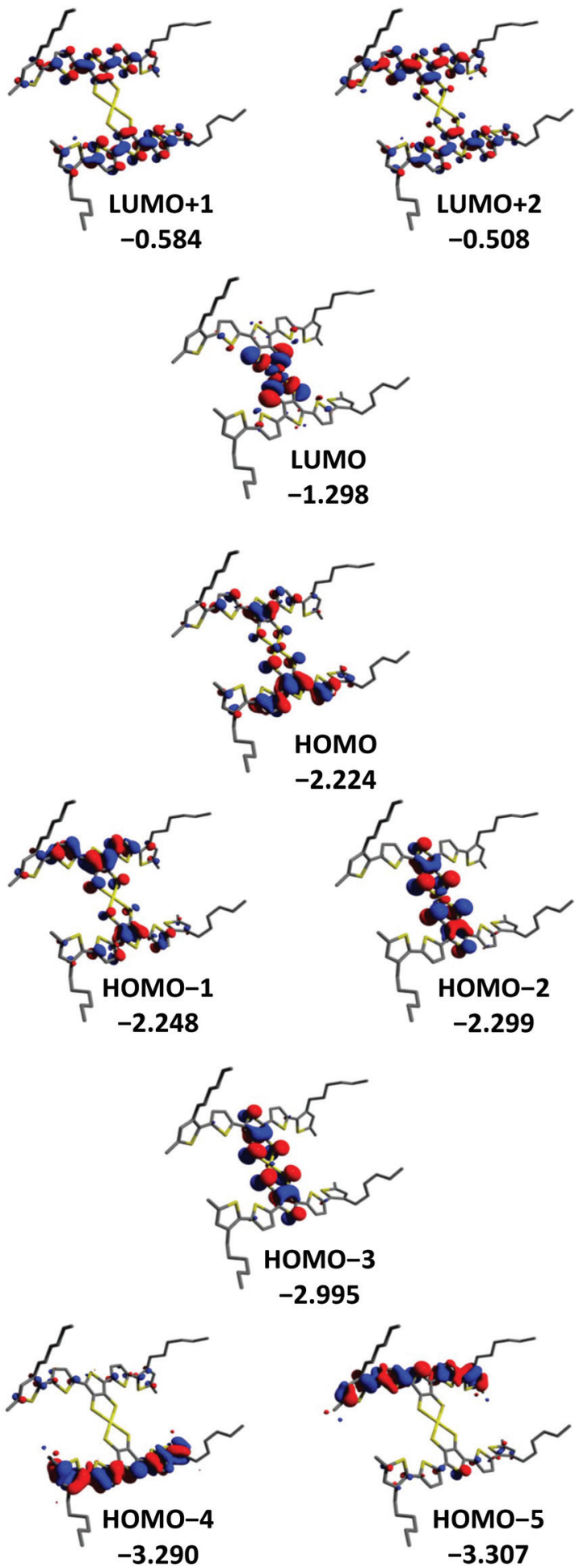

Fig. 5 Frontier orbital profiles and energies for the $\left[\mathrm{Au}(5 \mathrm{~T})_{2}\right]^{-}$anion.

the coordinating dithiolene sulfur atoms. This indicates that these orbitals make a much more substantial contribution to the shorter wavelength $\pi \rightarrow \pi^{*}$ transitions.

(5) The HOMO in $\left[\mathrm{Au}(3 \mathrm{TT})_{2}\right]^{-}$is quite similar to the HOMO-2 of $\left[\mathrm{Au}(\mathbf{5 T})_{2}\right]^{-}$. Noting that the energy differences between the HOMO, the HOMO-1 and the HOMO-2 are relatively small, it appears that the longer conjugation length of the 5T ligand leads to it having an increased influence on the frontier HOMOs than the less extended 3T ligand.

Paying particular attention to the mixed oligothiophene/ dithiolene nature of the HOMO orbitals, these results clearly indicate the presence of constructive electronic interplay between the ligands and the gold-dithiolene core. Overall, the calculated electronic structure of the gold TDT core agrees fairly well with existing studies on both gold dithiolenes ${ }^{64,65,71}$ and other metal TDT complexes. ${ }^{56}$

\section{Spectroelectrochemistry}

Neutral Au 34TDT complexes have not as yet been isolated. Upon oxidation of the monoanionic complexes with iodine they yield poorly defined and insoluble polycrystalline precipitates which show some paramagnetic character. ${ }^{39,42}$ UV-vis spectroelectrochemical (SEC) measurements present one route by which to begin to observe their spectral properties. SEC allows changes in a molecule's spectroscopic properties upon oxidation or reduction to be monitored.

Thin films of the complexes were deposited on ITO slides by drop casting. The slides were then suspended in an electrolytic solution and used as the working electrode of a standard three-electrode electrochemical cell held within a UV/vis spectrometer. A potential was applied to the film and its absorption spectrum measured at intervals of $+0.10 \mathrm{~V}$ in a step-wise fashion. Upon changing potential the film was given approximately 60 seconds to equilibrate prior to recording the spectrum. The results of these experiments are presented in Fig. 6. Spectroelectrochemical studies on thin films of the ligands $\mathbf{5 T}$ and $\mathbf{7 T}$ can be found in our previous publications. $^{57,58}$ The smallest ligand $3 \mathrm{~T}$ is soluble in the electrolyte solution therefore thin film studies were not possible.

Prior to oxidation, the thin film absorption spectra of all of the complexes are dominated by ligand based $\pi \rightarrow \pi^{*}$ transitions with the weak $\mathrm{d} \rightarrow \mathrm{d}$ transition of the $\mathrm{Au}$ dithiolene core also evident. Upon oxidation a large increase in absorption across the entire visible spectrum is observed, featuring characteristics of both the conjugated ligand and the delocalised Au dithiolene centre. This is a somewhat gradual process for $\left[\mathrm{Au}(3 \mathbf{T})_{2}\right]^{-}$and $\left[\mathrm{Au}(7 \mathbf{T})_{2}\right]^{-}$but is very sharp for $\left[\mathrm{Au}(\mathbf{5 T})_{2}\right]^{-}$ and remains remarkably stable at higher potentials.

The solid state SEC of bis(terthiophene) Au dithiolene complex $\left[\mathrm{Au}(3 \mathrm{~T})_{2}\right]^{-}$is shown in Fig. 6a. Upon increasing the potential from $0.00 \mathrm{~V}$ to $+0.40 \mathrm{~V}$ the intensity of the $\mathrm{d} \rightarrow \mathrm{d}$ absorption drops slightly then increases rapidly as at least one electron is lost with strong peaks emerging at 515 and $734 \mathrm{~nm}$. The wavelength of the first of these peaks is due to the terthiophene based radical cation while the second will occur over the now neutral $\left[\mathrm{AuC}_{4} \mathrm{~S}_{4}\right]^{0}$ dithiolene centre. The intensity of the absorbance across the spectrum begins to stabilise at potentials $>+0.70 \mathrm{~V}$.

The SEC plot for $\left[\mathrm{Au}(5 \mathrm{~T})_{2}\right]^{-}$(Fig. 6b) shows that upon oxidation at $+0.30 \mathrm{~V}$ a large and sudden spectral response occurs: the $\pi \rightarrow \pi^{*}$ absorption drops slightly in intensity and is red- 

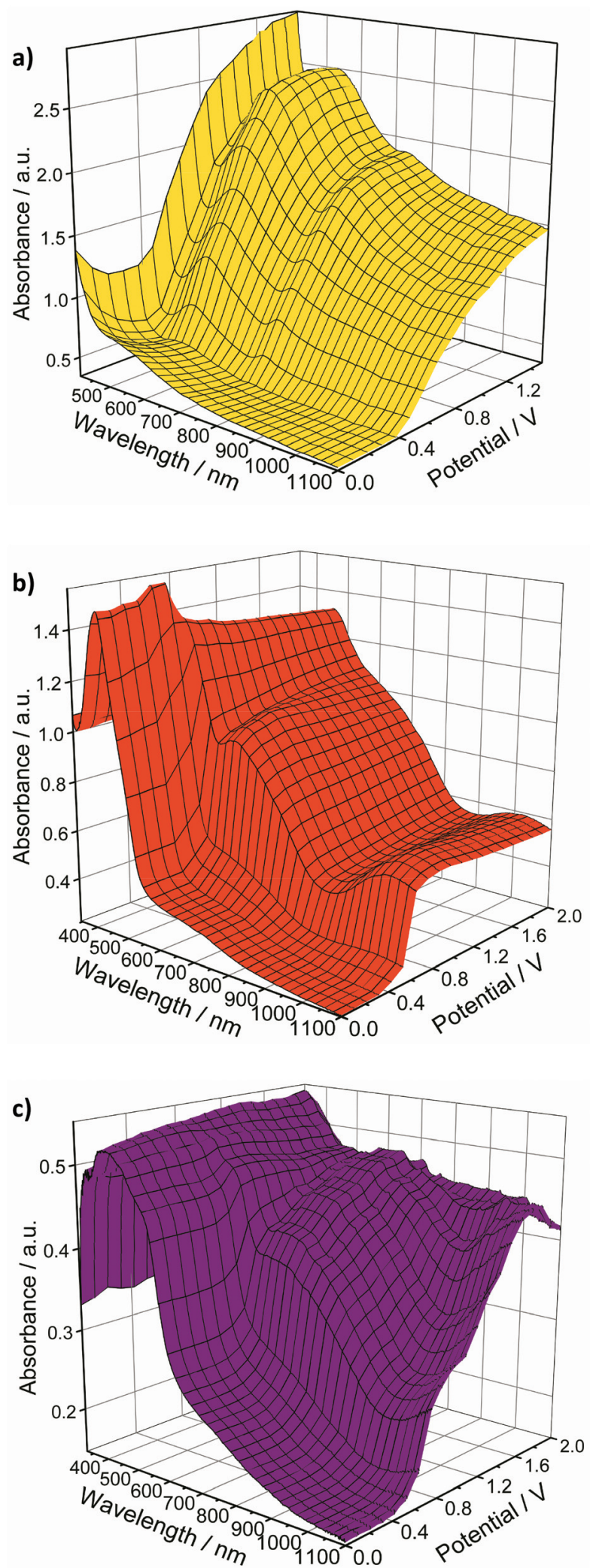

Fig. 6 Spectroelectrochemistry plots for the oxidation of thin films of (a) $\left[\mathrm{Au}(3 \mathrm{~T})_{2}\right]^{-}$, (b) $\left[\mathrm{Au}(5 \mathrm{~T})_{2}\right]^{-}$, and (c) $\left[\mathrm{Au}(7 \mathrm{~T})_{2}\right]^{-}$. shifted from 429 to $459 \mathrm{~nm}$ and this is typical behaviour observed in conjugated thiophene oligomers and polymers. ${ }^{72}$ Concomitantly, the intensity of absorption across the rest of the spectrum is raised greatly with peaks at $602 \mathrm{~nm}$ and $1036 \mathrm{~nm}$ pushing deep into the NIR. The very limited change in the spectrum at higher potentials may indicate that it has become insulating.

The complex $\left[\mathrm{Au}(7 \mathrm{~T})_{2}\right]^{-}$displays characteristics similar to those of the 5T analogue. At potentials above $+0.30 \mathrm{~V}$ the generation of broad bands with peaks at 679 and $>1100 \mathrm{~nm}$ respectively (Fig. 6c).

\section{X-Ray crystallography}

As previously mentioned, we attempted to synthesise nickel analogues of the gold complexes by using $\mathrm{NiCl}_{2} \cdot 6 \mathrm{H}_{2} \mathrm{O}$ in place of $\mathrm{K}(\mathrm{AuCl})_{4}$ but found them poorly stable and therefore difficult to isolate. However we were able to isolate a small amount of the terthiophene nickel complex by diffusion of cyclohexane into a tetrahydrofuran solution and were surprised by our findings.

A single crystal of $\left(\mathrm{Et}_{4} \mathrm{~N}\right)_{2}\left[\mathrm{Ni}(3 \mathrm{~T})_{2}\right]$ grew as an orange plate. $\mathrm{X}$-ray crystallography revealed that the complex displayed varying amounts of oxidation of the coordinating sulfur atoms. We can only attribute this partial oxidation to the complexes having reacted with dissolved molecular oxygen. Similar spontaneous aerobic oxidation of dithiolenes has only been reported on a small number of occasions. ${ }^{73-75}$ This behaviour also leads us to postulate that oxidation of our $\mathrm{Ni}$ complexes could be an underlying factor of their poor stability. The asymmetric unit of the nickel complex contains two half complexes with the Ni lying on an inversion centre and two tetraethylammonium cations (Fig. 7). The coordinated S atoms are partially oxidised and have two oxygen sites modelled for each $\mathrm{S}$ which are refined with a common occupancy for each pair (for $\mathrm{Ni}(1) 0.19(3)$ and $0.50(2)$, for $\mathrm{Ni}(1 \mathrm{a}) 0.24(2)$ and $0.42(2))$.

The terthiophene chains do not adopt the all-anti conformation typical of short chain oligothiophenes, presumably due to steric hindrance between the hexyl chains and possible

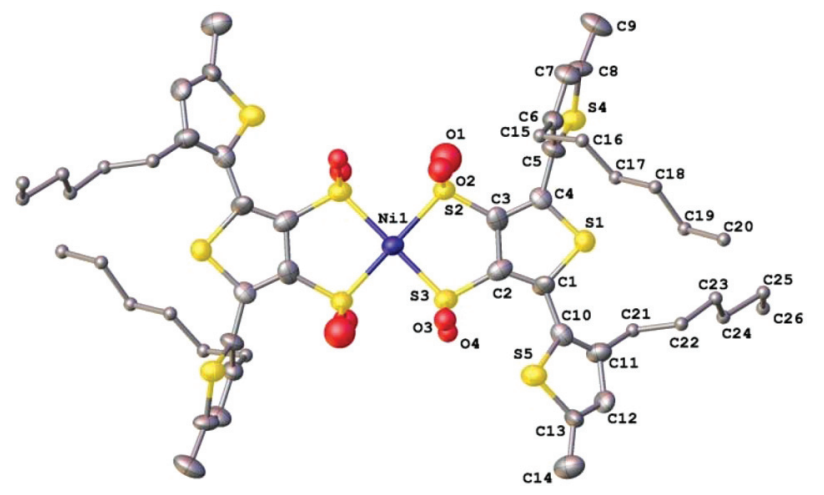

Fig. 7 X-ray molecular structure determined for the partially oxidised $\left[\mathrm{Ni}(3 \mathrm{~T})_{2}\right]^{2-}$ dianion. 
intermolecular forces between $\mathrm{S}(5) \cdots \mathrm{O}(3)(3.050(2))$. The torsional angles between the terminal thiophenes are $72(2)^{\circ}$ and $73(2)^{\circ}$ for $\mathrm{C} 3-\mathrm{C} 4-\mathrm{C} 5-\mathrm{C} 6$ and $\mathrm{C} 2 \mathrm{a}-\mathrm{C} 1 \mathrm{a}-\mathrm{C} 10 \mathrm{a}-\mathrm{C} 11 \mathrm{a}$ respectively and $150(2)^{\circ}$ and $148(2)$ for $\mathrm{C} 2-\mathrm{C} 1-\mathrm{C} 10-\mathrm{C} 11$ and $\mathrm{Ca}-\mathrm{C} 4 \mathrm{a}-$ C5a-C6a respectively. The root mean square deviation from planarity for the central dithiolene rings, Ni-S2-C3-C2-S3 and Ni1a-S2a-C3a-C2a-S3a are $0.067 \AA$ and $0.054 \AA$ respectively.

\section{Conclusions}

In conclusion, six new homoleptic bis(thiophene-3,4-dithiolate) complexes featuring nickel or gold metal centres bound between end-capped oligothiophene ligands with chain lengths of three, five and seven thiophenes were synthesised. The Ni complexes proved to be poorly stable due to facile autooxidation as confirmed by the isolation of a crystal of a partially oxidised complex, the molecular structure of which was confirmed by X-ray crystallography.

The monoanionic formally $\mathrm{Au}(\mathrm{III})$ complexes show hybrid optoelectronic properties resulting from interplay between the dithiolene core and the oligothiophene ligands including low oxidation potentials and a low energy metal centred absorption band, the position of which is sensitive to the oligothiophene chain length. This hybrid electronic behaviour has been confirmed using spectroscopic and electrochemical studies and corroborated with computational analysis of the two smaller complexes.

Spectroelectrochemical results for thin films of the $\mathrm{Au}(\mathrm{III})$ complexes in the solid state have shown that in all cases oxidation, ostensibly to the neutral Au(Iv) complex, results in a large and sudden increase in the intensity of absorption across the entire visible window and into the NIR, which persists at higher potentials. Although their isolation remains challenging, the interesting optoelectronic and magnetic properties of neutral gold 34TDT complexes with extended conjugation means that they remain intriguing targets for further development. In particular, their broad and strong absorption across the visible and NIR regions of the spectrum make them excellent candidate materials for broadband light sensing and harvesting applications. $^{76}$

\section{Conflicts of interest}

There are no conflicts to declare.

\section{Acknowledgements}

PJS and IAW acknowledge the EPSRC for funding. IAW acknowledges Loughborough University and the Royal Society of Chemistry Research Fund (Grant No. RF18-5353) for funding.

\section{Notes and references}

1 G. N. Schrauzer and V. Mayweg, J. Am. Chem. Soc., 1962, 84, 3221.

2 H. B. Gray, R. Williams, I. Bernal and E. Billig, J. Am. Chem. Soc., 1962, 84, 3596-3597.

3 A. Davison, N. Edelstein, R. H. Holm and A. H. Maki, Inorg. Chem., 1963, 2, 1227-1232.

$4 \mathrm{~J}$. A. McCleverty, in Progress in Inorganic Chemistry, ed. F. A. Cotton, John Wiley \& Sons, Inc., Hoboken, NJ, USA, 1968, vol. 10, pp. 49-221.

5 R. Eisenberg and H. B. Gray, Inorg. Chem., 2011, 50, 97419751.

6 M. L. Kirk, R. L. McNaughton and M. E. Helton, in Dithiolene Chemistry. Synthesis, Properties, and Applications. Progress in Inorganic Chemistry, ed. E. I. Stiefel and K. D. Karlin, John Wiley \& Sons, Inc., Hoboken, NJ, USA, 2004, vol. 52, pp. 111-212.

7 S. D. Cummings and R. Eisenberg, in Dithiolene Chemistry: Synthesis, Properties, and Applications. Progress in Inorganic Chemistry, ed. E. I. Stiefel and K. D. Karlin, John Wiley \& Sons, Inc., Hoboken, NJ, USA, 2004, vol. 52, pp. 315-367.

8 K. Wang, in Dithiolene Chemistry: Synthesis, Properties, and Applications. Progress in Inorganic Chemistry, ed. E. I. Stiefel and K. D. Karlin, John Wiley \& Sons, Inc., Hoboken, NJ, USA, 2004, vol. 52, pp. 267-314.

9 N. Robertson and L. Cronin, Coord. Chem. Rev., 2002, 227, 93-127.

10 R. Kato, Chem. Rev., 2004, 104, 5319-5346.

11 M. Bousseau, L. Valade, J. P. Legros, P. Cassoux, M. Garbauskas and L. V. Interrante, J. Am. Chem. Soc., 1986, 108, 1908-1916.

12 D. G. Branzea, F. Pop, P. Auban-Senzier, R. Clérac, P. Alemany, E. Canadell and N. Avarvari, J. Am. Chem. Soc., 2016, 138, 6838-6851.

13 T. D. Anthopoulos, G. C. Anyfantis, G. C. Papavassiliou and D. M. De Leeuw, Appl. Phys. Lett., 2007, 90, 122105.

14 T. D. Anthopoulos, S. Setayesh, E. Smits, M. Cölle, E. Cantatore, B. De Boer, P. W. M. Blom and D. M. De Leeuw, Adv. Mater., 2006, 18, 1900-1904.

15 S. Dalgleish, J. G. Labram, Z. Li, J. Wang, C. R. McNeill, T. D. Anthopoulos, N. C. Greenham and N. Robertson, J. Mater. Chem., 2011, 21, 15422-15430.

16 P. Deplano, L. Pilia, D. Espa, M. L. Mercuri and A. Serpe, Coord. Chem. Rev., 2010, 254, 1434-1447.

17 D. Espa, L. Pilia, C. Makedonas, L. Marchiò, M. L. Mercuri, A. Serpe, A. Barsella, A. Fort, C. A. Mitsopoulou and P. Deplano, Inorg. Chem., 2014, 53, 1170-1183.

18 A. Zarkadoulas, E. Koutsouri and C. A. Mitsopoulou, Coord. Chem. Rev., 2012, 256, 2424-2434.

19 W. R. McNamara, Z. Han, C.-J. Yin, W. W. Brennessel, P. L. Holland and R. Eisenberg, Proc. Natl. Acad. Sci. U. S. A., 2012, 109, 15594-15599.

20 W. R. McNamara, Z. Han, P. J. Alperin, W. W. Brennessel, P. L. Holland and R. Eisenberg, J. Am. Chem. Soc., 2011, 133, 15368-15371. 
21 J. Roncali, Chem. Rev., 1992, 92, 711-738.

22 T. P. Kaloni, P. K. Giesbrecht, G. Schreckenbach and M. S. Freund, Chem. Mater., 2017, 29, 10248-10283.

23 A. L. Kanibolotsky, N. J. Findlay and P. J. Skabara, Beilstein J. Org. Chem., 2015, 11, 1749-1766.

24 T. M. S. K. Pathiranage, D. S. Dissanayake, C. N. Niermann, Y. Ren, M. C. Biewer and M. C. Stefan, J. Polym. Sci., Part A: Polym. Chem., 2017, 55, 3327-3346.

25 A. Mishra, C. Q. Ma and P. Bäuerle, Chem. Rev., 2009, 109, 1141-1176.

26 L. Zhang, N. S. Colella, B. P. Cherniawski, S. C. B. Mannsfeld and A. L. Briseno, ACS Appl. Mater. Interfaces, 2014, 6, 5327-5343.

27 T. Otsubo, Y. Aso and K. Takimiya, J. Mater. Chem., 2002, 12, 2565-2575.

28 C. L. Kean and P. G. Pickup, Chem. Commun., 2001, 815-816.

29 C. L. Kean, D. O. Miller and P. G. Pickup, J. Mater. Chem., 2002, 12, 2949-2956.

30 T. Anjos, S. J. Roberts-Bleming, A. Charlton, N. Robertson, A. R. Mount, S. J. Coles, M. B. Hursthouse, M. Kalaji and P. J. Murphy, J. Mater. Chem., 2008, 18, 475-483.

31 S. Dalgleish, C. A. Morrison, D. S. Middlemiss, A. R. Mount, A. Collins, L. Pilia, A. Serpe, M. L. Mercuri, S. J. Roberts-Bleming, A. Charlton, P. Deplano, P. J. Murphy and N. Robertson, J. Mater. Chem., 2009, 19, 6194-6200.

32 S. Dalgleish and N. Robertson, Coord. Chem. Rev., 2010, 254, 1549-1558.

33 C. Pozo-Gonzalo, R. Berridge, P. J. Skabara, E. Cerrada, M. Laguna, S. J. Coles and M. B. Hursthouse, Chem. Commun., 2002, 2408-2409.

34 P. J. Skabara, C. Pozo-Gonzalo, N. Lardiés Miazza, M. Laguna, E. Cerrada, A. Luquin, B. González, S. J. Coles, M. B. Hursthouse, R. W. Harrington and W. Clegg, Dalton Trans., 2008, 3070-3079.

35 S. Dalgleish, H. Yoshikawa, M. M. Matsushita, K. Awaga and N. Robertson, Chem. Sci., 2011, 2, 316-320.

36 E. Allwright, G. Silber, J. Crain, M. M. Matsushita, K. Awaga and N. Robertson, Dalton Trans., 2016, 45, 9363-9368.

37 J. Wang, L.-X. Shi, J.-Y. Wang, J.-X. Chen, S.-H. Liu and Z.-N. Chen, Dalton Trans., 2017, 46, 2023-2029.

38 D. Belo, H. Alves, E. B. Lopes, V. Gama, R. T. Henriques, M. T. Duarte, M. Almeida, A. Perez-Benitez, C. Rovira and J. Veciana, Synth. Met., 2001, 120, 699-702.

39 D. Belo, H. Alves, E. B. Lopes, M. T. Duarte, V. Gama, R. Teives Henriques, M. Almeida, A. Pérez-Benítez, C. Rovira and J. Veciana, Chem. - Eur. J., 2001, 7, 511-519.

40 D. Belo, M. J. Figueira, J. Mendonça, I. C. Santos, M. Almeida, R. T. Henriques, M. T. Duarte, C. Rovira and J. Veciana, Eur. J. Inorg. Chem., 2005, 3337-3345.

41 A. I. S. Neves, I. C. Santos, D. Belo and M. Almeida, CrystEngComm, 2009, 11, 1046-1053.

42 D. Belo and M. Almeida, Coord. Chem. Rev., 2010, 254, 1479-1492.

43 D. Belo, H. Alves, S. Rabaça, L. C. Pereira, M. T. Duarte, V. Gama, R. T. Henriques, M. Almeida, E. Ribera, C. Rovira and J. Veciana, Eur. J. Inorg. Chem., 2001, 2001, 3127-3133.
44 D. Belo, M. J. Figueira, J. P. M. Nunes, I. C. Santos, L. C. Pereira, V. Gama, M. Almeida and C. Rovira, J. Mater. Chem., 2006, 16, 2746-2756.

45 J. P. M. Nunes, M. J. Figueira, D. Belo, I. C. Santos, B. Ribeiro, E. B. Lopes, R. T. Henriques, J. Vidal-Gancedo, J. Veciana, C. Rovira and M. Almeida, Chem. - Eur. J., 2007, 13, 9841-9849.

46 D. Belo, J. Mendonça, I. C. Santos, L. C. J. Pereira, M. Almeida, J. J. Novoa, C. Rovira, J. Veciana and V. Gama, Eur. J. Inorg. Chem., 2008, 5327-5337.

47 D. Belo, L. C. Jesus Pereira, M. Almeida, C. Rovira, J. Veciana and V. Gama, Dalton Trans., 2009, 4176-4180.

48 A. I. S. Neves, J. C. Dias, B. J. C. Vieira, I. C. Santos, M. B. Castelo Branco, L. C. J. Pereira, J. C. Waerenborgh, M. Almeida, D. Belo and V. da Gama, CrystEngComm, 2009, 11, 2160-2168.

49 A. I. S. Neves, I. C. Santos, L. C. J. Pereira, C. Rovira, E. Ruiz, D. Belo and M. Almeida, Eur. J. Inorg. Chem., 2011, 4807-4815.

50 D. Belo, A. I. S. Neves, L. C. J. Pereira and M. Almeida, Phys. Status Solidi, 2012, 9, 1199-1201.

51 E. Laukhina, V. Lebedev, V. Laukhin, A. P. del Pino, E. B. Lopes, A. I. S. Neves, D. Belo, M. Almeida, J. Veciana and C. Rovira, Org. Electron., 2012, 13, 894-898.

52 R. Silva, B. Vieira, M. Andrade, I. Santos, S. Rabaça, E. Lopes, J. Coutinho, L. Pereira, M. Almeida and D. Belo, Molecules, 2018, 23, 424.

53 A. I. S. Neves, I. C. Santos, J. T. Coutinho, L. C. J. Pereira, R. T. Henriques, E. B. Lopes, H. Alves, M. Almeida and D. Belo, Eur. J. Inorg. Chem., 2014, 2014, 3989-3999.

54 T. Higashino, O. Jeannin, T. Kawamoto, D. Lorcy, T. Mori and M. Fourmigué, Inorg. Chem., 2015, 54, 9908-9913.

55 C. M. Amb and S. C. Rasmussen, Synth. Met., 2009, 159, 2390-2393.

56 C. M. Amb, C. L. Heth, S. J. Evenson, K. I. Pokhodnya and S. C. Rasmussen, Inorg. Chem., 2016, 55, 10978-10989.

57 I. A. Wright, P. J. Skabara, J. C. Forgie, A. L. Kanibolotsky, B. González, S. J. Coles, S. Gambino and I. D. W. Samuel, J. Mater. Chem., 2011, 21, 1462-1469.

58 I. A. Wright, N. J. Findlay, S. Arumugam, A. R. Inigo, A. L. Kanibolotsky, P. Zassowski, W. Domagala and P. J. Skabara, J. Mater. Chem. C, 2014, 2, 2674-2683.

59 R. G. D. Taylor, J. Cameron, I. A. Wright, N. Thomson, O. Avramchenko, A. L. Kanibolotsky, A. R. Inigo, T. Tuttle and P. J. Skabara, Beilstein J. Org. Chem., 2015, 11, 1148-1154. 60 I. A. Wright, A. L. Kanibolotsky, J. Cameron, T. Tuttle, P. J. Skabara, S. J. Coles, C. T. Howells, S. A. J. Thomson, S. Gambino and I. D. W. Samuel, Angew. Chem., Int. Ed., 2012, 51, 4562-4567.

61 S. Arumugam, I. A. Wright, A. R. Inigo, S. Gambino, C. T. Howells, A. L. Kanibolotsky, P. J. Skabara and I. D. W. Samuel, J. Mater. Chem. C, 2014, 2, 34-39.

62 P. J. Skabara, I. M. Serebryakov, D. M. Roberts, I. F. Perepichka, S. J. Coles and M. B. Hursthouse, J. Org. Chem., 1999, 64, 6418-6424.

63 F. S. Guziec, J. M. Russo, F. F. Torres, G. C. Long and M. R. Tellez, J. Chem. Soc., Perkin Trans. 1, 1989, 1068-1070. 
64 K. Ray, T. Weyhermüller, F. Neese and K. Wieghardt, Inorg. Chem., 2005, 44, 5345-5360.

65 N. C. Schiodt, P. Sommer-Larsen, T. Bjornholm, M. F. Nielsen, J. Larsen and K. Bechgaard, Inorg. Chem., 1995, 34, 3688-3694.

66 K. Ray, T. Weyhermüller, A. Goossens, M. W. J. Crajé and K. Wieghardt, Inorg. Chem., 2003, 42, 4082-4087.

67 L. Y. Chiang, P. Shu, D. Holt and D. Cowan, J. Org. Chem., 1983, 48, 4713-4717.

68 X. Chen, N. R. de Tacconi and R. L. Elsenbaumer, J. Org. Chem., 2009, 74, 9188-9190.

69 D. Williams and I. Fleming, Spectroscopic Methods in Organic Chemistry, McGraw-Hill Publishing Company, London, 5th edn, 1995.

70 C. Wang, J. L. Schindler, C. R. Kannewurf and M. G. Kanatzidis, Chem. Mater., 1995, 7, 58-68.
71 S. Kokatam, K. Ray, J. Pap, E. Bill, W. E. Geiger, R. J. LeSuer, P. H. Rieger, T. Weyhermüller, F. Neese and K. Wieghardt, Inorg. Chem., 2007, 46, 1100-1111.

72 R. Berridge, S. P. Wright, P. J. Skabara, A. Dyer, T. Steckler, A. A. Argun, J. R. Reynolds, R. W. Harrington and W. Clegg, J. Mater. Chem., 2007, 17, 225-231.

73 G. N. Schrauzer, C. Zhang and R. Chadha, Inorg. Chem., 1990, 29, 4104-4107.

74 R. Bolligarla and S. K. Das, Eur. J. Inorg. Chem., 2012, 2012, 2933-2939.

75 E. J. Uzelac and S. C. Rasmussen, Eur. J. Inorg. Chem., 2017, 2017, 3878-3883.

76 D. Cortizo-Lacalle, C. T. Howells, S. Gambino, F. Vilela, Z. Vobecka, N. J. Findlay, A. R. Inigo, S. A. J. Thomson, P. J. Skabara and I. D. W. Samuel, J. Mater. Chem., 2012, 22, 14119-14126. 